\title{
Bacteria of the genus Endozoicomonas dominate the microbiome of the Mediterranean gorgonian coral Eunicella cavolini
}

\author{
Till Bayer ${ }^{1, *}$, Chatchanit Arifi ${ }^{1}$, Christine Ferrier-Pagès ${ }^{2}$, Didier Zoccola ${ }^{2}$, \\ Manuel Aranda ${ }^{1}$, Christian R. Voolstra ${ }^{1, *}$ \\ ${ }^{1}$ Red Sea Research Center, King Abdullah University of Science and Technology, 23955 Thuwal, Kingdom of Saudi Arabia \\ ${ }^{2}$ Centre Scientifique de Monaco, 98000 Monaco, Monaco
}

\begin{abstract}
Forming dense beds that provide the structural basis of a distinct ecosystem, the gorgonian Eunicella cavolini (Octocorallia) is an important species in the Mediterranean Sea. Despite the importance and prevalence of this temperate gorgonian, little is known about its microbial assemblage, although bacteria are well known to be important to hard and soft coral functioning. Here, we used massively parallel pyrosequencing of $16 \mathrm{~S}$ rRNA genes to determine the composition and relative abundances of bacteria associated with $E$. cavolini collected from different depths at a site on the French Mediterranean coast. We found that whereas the bacterial assemblages of E. cavolini were distinct and less diverse than those of the surrounding water column, the water depth did not affect the bacterial assemblages of this gorgonian. Our data show that E. cavolini's microbiome contains only a few shared species and that it is highly dominated by bacteria from the genus Endozoicomonas, a Gammaproteobacteria that is frequently found to associate with marine invertebrates.
\end{abstract}

KEY WORDS: Microbial communities · Gorgonian · Eunicella cavolini · 16S tag sequencing Resale or republication not permitted without written consent of the publisher

\section{INTRODUCTION}

Associations between marine invertebrates and prokaryotes have commonly been observed. Some of the best studied examples are from the benthic fauna found near hot vents and cold seeps, where mussels and tubeworms live in tight symbiotic association with bacteria and take advantage of the energy produced by the bacteria (see Dubilier et al. 2008 for review). Other marine host species rely on heterotrophic bacteria to metabolize otherwise inaccessible organic compounds. For instance, at whale fall sites, the Osedax worm lives in symbiosis with bacteria of the order Oceanospirillales. These bacteria are thought to break down organic compounds in whale bone, providing nutrition to the worm (Rouse et al. 2004). In addition to nutritional interactions, such partnerships can facilitate other beneficial processes, as in the squid Euprymna scolopes, which hosts Vibrio fisheri bacteria in a specialized light organ that provides nightly camouflage from predators (McFallNgai 2008).

Prokaryotes also play important roles in the functioning of scleractinian tropical reef corals. Speciesspecific coral-bacterial associations exist across distant locations for some coral species (Rohwer et al. 2002, Sharp et al. 2012), but not for others (Morrow et al. 2012). Microbes provide benefits to corals, such as nitrogen fixation (Williams et al. 1987, Shashar et al. 1994, Rohwer et al. 2002, Lesser et al. 2004), antibi- 
otic production (Ritchie 2006), mucus recycling and food supply (Ferrier-Pages et al. 2000, Wild et al. 2004). However, microbes can also be agents of coral diseases when environmental conditions are not optimal (Frias-Lopez et al. 2002, Pantos et al. 2003, Bourne \& Munn 2005). In studies of tropical octocorallia (Gorgonacea), the focus has been on antimicrobial activity (Cimino et al. 1984, Roussis et al. 2001, Couch et al. 2008) or microbial diseases, particularly those that affect sea fans (Bruno et al. 2007, Mydlarz et al. 2008, Rivest et al. 2010).

In comparison with tropical anthozoans, there are only a few studies on the microbial associations of temperate anthozoans, such as Mediterranean gorgonians (Rivière et al. 2010). These gorgonians are among the most representative and structurally important species of the Mediterranean coastal benthos (Gili \& Ros 1985). The diversity and richness of the habitats they form are often compared to those of tropical coral reefs (Ballesteros 2006). Gorgonians can develop very dense populations (Weinbauer \& Velimirov 1995) and therefore play an important role as ecosystem engineers (Jones et al. 1994) by providing biomass and structural complexity (Harmelin 1995). They are also important drivers of energy and matter from the planktonic to the benthic ecosystem (Gili \& Coma 1998). Like many of the $\sim 20$ described gorgonian species that inhabit the Mediterranean Sea (Carpine \& Grasshoff 1975), Eunicella cavolini (Koch, 1887) occurs from the surface to $100 \mathrm{~m}$ depth (Gili et al. 1989, Harmelin 1995). It is one of the most abundant structural species within the rocky sublittoral zone (Gili \& Ros 1985, Harmelin 1995, Ballesteros 2006). Mediterranean gorgonians exhibit slow growth rates and low natural mortality rates (Harmelin 1995, Gili \& Coma 1998, Linares et al. 2007, Bramanti et al. 2009); they are, however, especially vulnerable to anthropogenic disturbances and climatic anomalies (Garrabou \& Harmelin 2002, Santangelo et al. 2007, Linares \& Doak 2010), which have increasingly induced mass mortality events (Linares et al. 2005, Coma et al. 2006, Garrabou et al. 2009). These mortality events often occur during summer when the temperature is abnormally high and when there is strong stratification, inducing nutrient depletion and pathogen colonization (Cerrano et al. 2000). A Vibrio strain with thermo-dependent virulence was isolated from diseased colonies of Paramuricea clavata (Gorgonacea), suggesting that pathogenic bacteria play a role in gorgonian mortality events (Bally \& Garrabou 2007).

Despite the increasing threats to gorgonians and their importance to the Mediterranean benthic eco- system, the composition of the microbial communities living in association with Eunicella cavolini remains completely unknown. We therefore sought to study the bacterial assemblage found in healthy colonies of E. cavolini, to elucidate whether the community composition changes with depth, and to discover whether E. cavolini has a clearly defined core microbiome. These data will serve as a reference and baseline to further investigate changes in the composition and functions of microbiota resulting from elevated temperatures, disease, and other environmental stressors.

\section{MATERIALS AND METHODS}

\section{Sampling and DNA extraction}

Eunicella cavolini individuals were sampled in the Bay of Villefranche-sur-Mer on the French Mediterranean coast ( $\left.43^{\circ} 41^{\prime} 10^{\prime \prime} \mathrm{N}, 7^{\circ} 19^{\prime} 0^{\prime \prime} \mathrm{E}\right)$ in June 2010. Samples were collected using SCUBA from 3 depths $(24,30$, and $41 \mathrm{~m}, \mathrm{n}=3$ at each depth). This zone is characterized as oligotrophic with low concentrations of inorganic and organic nutrients (BustillosGuzmán et al. 1995, Lacroix \& Nival 1998). The maximum depth at the study site was $80 \mathrm{~m}$. The gorgonian colonies were found to be attached to the rocky substrate. The sampled individuals were separated by several meters $(>3 \mathrm{~m})$. There were no signs of disease, necrosis, or mortality in the samples or surrounding colonies during the months around the collection time. At each sampling depth, several branches from 3 different colonies were cut with clean scissors, individually enclosed in sterile plastic bags and brought back to the laboratory. The gorgonians were then rinsed with $0.2 \mu \mathrm{m}$ filtered seawater and flash-frozen in liquid nitrogen until DNA extraction. We named the 3 samples collected at $24 \mathrm{~m} \mathrm{G} 24 \mathrm{~A}, \mathrm{G} 24 \mathrm{~B}$, and $\mathrm{G} 24 \mathrm{C}$, those at $30 \mathrm{~m}$ G30A, G30B, G30C and those at $41 \mathrm{~m} \mathrm{G} 41 \mathrm{~A}, \mathrm{G} 41 \mathrm{~B}$, G41C. To identify bacterial communities that were also found in the surrounding seawater, we collected seawater in the vicinity of the sampled colonies. We named these 3 samples W24, W30, and W41, according to the depth at which they were sampled. To isolate the bacteria in the seawater samples, we filtered 2 to 31 samples from each depth under low pressure on $0.2 \mu \mathrm{m}$ Isopore $25 \mathrm{~mm}$ filters (Millipore). The filters were subsequently flash-frozen for downstream analyses. DNA was extracted from the gorgonian samples by crushing whole tissue samples in liquid nitrogen to a powder 
and then processing $500 \mathrm{mg}$ of each powder sample with a commercially available extraction kit (MoBio) according to Rohwer et al. (2002). The same kit was also used to extract DNA from one half of each filter.

\section{PCR amplification of 16 S rDNA}

To obtain an amplicon of a size suitable for 454 sequencing, the 27F (5'-CGT ATC GCC TCC CTC GCG CCA TCA GNN NNN NNN tcAGA GTT TGA TCC TGG CTC AG-3') and 338R (5'-CTA TGC GCC TTG CCA GCC CGC TCA GcaTG CTG CCT CCC GTA GGA GT-3') primers were used to amplify variable regions 1 and 2 of the $16 \mathrm{~S}$ rRNA gene. Both primers contained Roche 454 pyrosequencing adaptors (underlined above) for use in the library construction, as well as a 2-bp linker sequence (lowercase) to prevent tag or adapter influence on the polymerase chain reaction (PCR) (Berry et al. 2011). The forward primer also contained a sample-specific barcode sequence (indicated as N). PCR was performed using a Qiagen Multiplex PCR kit with $2 \mu \mathrm{M}$ of each primer adjusted to a final volume of $25 \mu$ with RNAsefree water. For the gorgonian samples, 2 ng DNA were used as the template. The DNA extracted from the filters was below the detection limit for the photometer used, but a 1:10 dilution of the extraction was sufficient to yield ample PCR product, whereas a negative control did not amplify. The temperature cycling for amplification was as follows: 1 cycle at $95^{\circ} \mathrm{C}$ for $15 \mathrm{~min}$; 30 cycles at $94^{\circ} \mathrm{C}$ for $45 \mathrm{sec}, 60^{\circ} \mathrm{C}$ for $30 \mathrm{sec}$ and $72^{\circ} \mathrm{C}$ for $40 \mathrm{sec}$ and 1 final extension at $72^{\circ} \mathrm{C}$ for $10 \mathrm{~min}$. All reactions were performed in duplicate. The PCR products were quantified using a Qubit photometer (Invitrogen) and then pooled in equal amounts after purification with a Qiagen PCR purification kit. Sequencing was performed using the Roche 454 FLX using titanium chemistry.

Full-length 16S sequences of Endozoicomonas were obtained via PCR from 3 samples (G30B, G30C, G41A) that had large percentages of this bacteria (as determined by 454 sequencing analysis) using the primers $27 \mathrm{~F}$ (5'-AGA GTT TGA TCC TGG CTC AG-3') and 1492R (5'-GGT TAC CTT GTT ACG ACT T-3'). The PCR product was cloned using a Qiagen PCR Cloning Kit and sequenced in both directions on a capillary sequencer. Thirty clones were sequenced, 20 of which originated from Endozoicomonas.

\section{Data analysis}

We used mothur (version 1.16.1), an open-source software developed for microbial ecology data analysis, for most steps (Schloss et al. 2009). Sequence reads were split according to barcodes and quality trimmed to an average quality of 27 in a $50 \mathrm{bp}$ window. These reads were aligned against the SILVA alignment database (release 108; Pruesse et al. 2007), and we removed any sequences that did not cover variable regions 1 and 2 (SILVA alignment positions 1044 to 5436). To reduce sequencing noise, a preclustering step as implemented in mothur (1 bp difference) was performed (Huse et al. 2010). Chimeric sequences were removed using UCHIME as implemented in mothur (Edgar et al. 2011). Sequences are available in the NCBI Sequence Read Archive under accession number SRA050215.1.

Beta diversity based on the Yue and Clayton theta measure for dissimilarity (Yue \& Clayton 2005) was calculated in mothur based on a dataset subsampled to the minimal number of reads in any sample (2580). In addition ANOSIM analyses were used to test for differences between sample groups based on the YueClayton theta, which were calculated with the anosim command in the vegan package (Oksanen et al. 2012), within the R Statistical Package (R Core Team 2012). As an alternative beta diversity measure weighted UniFrac (Lozupone \& Knight 2005) was calculated with mothur, also based on the subsampled dataset.

The association of single operational taxonomic units (OTU) to sample groups was calculated using the indicspecies package (De Cáceres \& Legendre 2009), also within the R Statistical Package (R Core Team 2012). We performed 2 tests with different partitions of the data, the first splitting the samples into water and gorgonians and the second grouping just the gorgonian samples by depth.

Full-length clone sequences were vector- and quality-trimmed with CodonCode Aligner 3.7.1, aligned to the SILVA database (release 108) using the SINA aligner available on the SILVA website (Pruesse et al. 2007) and subsequently imported into ARB version 5.1 (Ludwig et al. 2004). The sequences are available in Genbank under accession numbers JQ691564 to JQ691583. With these full-length sequences as well as related sequences available in SILVA, a maximum likelihood phylogenetic tree was generated using PhyML (Guindon \& Gascuel 2003), as implemented in ARB, with a GTR model and 1000 bootstraps. Additionally, a neighborhood-joining tree with 1000 bootstraps was calculated in MEGA version 5 (Tamura et al. 2011) using the Jukes Cantor correction. 
Table 1. Eunicella cavolini. Gorgonian coral and water samples taken in Bay of Villefranche-sur-Mer on the French Mediterranean coast: depth of collection, number of sequences and operational taxonomic units at the 0.03 difference level (OTUs), and alpha diversity measures

\begin{tabular}{|c|c|c|c|c|c|c|c|}
\hline $\begin{array}{l}\text { Sample } \\
\text { code }\end{array}$ & $\begin{array}{l}\text { Depth } \\
\text { (m) }\end{array}$ & $\begin{array}{c}\text { No. of } \\
\text { sequences }\end{array}$ & $\begin{array}{l}\text { No. of } \\
\text { OTUs }\end{array}$ & $\begin{array}{l}\text { Inverse Simpson } \\
\text { index }\end{array}$ & $\begin{array}{l}\text { Shannon } \\
\text { index }\end{array}$ & Chao1 & $\begin{array}{l}\text { Shannon } \\
\text { evenness }\end{array}$ \\
\hline \multicolumn{8}{|c|}{ Water samples } \\
\hline W24 & 24 & 29812 & 1711 & 35.44 & 4.87 & 2911.0 & 0.65 \\
\hline W30 & 30 & 30765 & 1199 & 19.01 & 4.23 & 2039.0 & 0.60 \\
\hline W41 & 41 & 34859 & 1734 & 31.09 & 4.68 & 3676.7 & 0.63 \\
\hline \multicolumn{8}{|c|}{ E. cavolini samples } \\
\hline G24A & 24 & 7900 & 785 & 16.14 & 4.43 & 1199.6 & 0.67 \\
\hline G24B & 24 & 13427 & 119 & 1.32 & 0.79 & 162.3 & 0.17 \\
\hline $\mathrm{G} 24 \mathrm{C}$ & 24 & 2580 & 136 & 3.39 & 2.21 & 232.6 & 0.45 \\
\hline G30A & 30 & 18256 & 704 & 5.64 & 3.44 & 1176.1 & 0.52 \\
\hline G30B & 30 & 5555 & 147 & 1.73 & 1.29 & 233.0 & 0.26 \\
\hline G30C & 30 & 4424 & 156 & 1.65 & 1.38 & 217.2 & 0.27 \\
\hline G41A & 41 & 10028 & 132 & 1.15 & 0.52 & 254.2 & 0.11 \\
\hline G41B & 41 & 3315 & 100 & 2.46 & 1.52 & 151.8 & 0.33 \\
\hline G41C & 41 & 3448 & 413 & 5.07 & 3.61 & 638.0 & 0.60 \\
\hline
\end{tabular}

\section{RESULTS}

We produced 528977 reads from 12 samples, 3 water samples and 3 gorgonian colonies collected from 3 depths $(24,30$, and $41 \mathrm{~m}, \mathrm{n}=9$, Table 1). Of these reads, 164369 were used for analysis after quality trimming and chimera detection (water samples: 95436 reads, length $228.9 \pm 0.05 \mathrm{bp}$, average \pm $\mathrm{SE}$; gorgonian samples: 68933 reads, length $242.9 \pm$ $0.04 \mathrm{bp}$ ). The water samples were thus represented by more sequences in our library with about a 4 -fold higher number on average (Table 1). We clustered all sequences at the 0.03 difference level to obtain OTUs. The bacterial community of the seawater was much more diverse than that in the gorgonian tissues (inverse Simpson index, Mann-Whitney $U$ test between all 3 water samples and all 9 gorgoninan samples, $\mathrm{p}=0.0091$ ). The difference in diversity is caused by both the number of OTUs and the evenness. Observed counts of OTUs, as well as the Chao 1 estimate of species richness (Chao 1984), are higher in the water samples, as is the evenness (Table 1). The much higher diversity was also reflected in rarefaction curves for the different samples. Although the number of sequences was much higher for the water samples, their curves did not reach a plateau (Fig. S1 in the Supplement at www.int-res.com/articles/suppl/ m479p075_supp.pdf). This indicates that more sequencing would be necessary to capture the complete diversity of the bacteria present. The diversity data for the gorgonian samples was significantly lower than for water, but not homogeneous within the gorgonian samples. In each of the groups of replicates, one had a higher diversity as compared with the others. These were G24A, G30A and G41C (Table 1).

We were interested in the differences in the bacterial communities between the water and gorgonian samples, as well as among the gorgonian samples from different depths. We compared the community structure of the samples using an OTU-based approach. We used the Yue and Clayton measure of dissimilarity (Yue \& Clayton 2005) to calculate a distance matrix, and then generated a UPGMA tree and a heatmap based on this matrix (Fig. 1). The water samples were clearly separated from all gorgonian samples, indicating that the bacterial communities were considerably different (ANOSIM $\mathrm{p}=0.006$ ). Within the gorgonian samples, no structuring according to sampling depth was apparent (ANOSIM p = 0.99). Furthermore, the replicate samples from each depth did not cluster together. The G24A sample, which exhibited much higher diversity than all other gorgonian samples, was far removed from the remaining gorgonian samples in the tree (Fig. 1). Interestingly, G30A and G41C (the other 2 samples with high diversity) were not far removed from the rest, but close to each other (Fig. S2 in the Supplement).

In addition to the analysis based on OTU clustering, we generated a tree with all sequences to analyze differences in community composition between samples. Here, we used weighted Unifrac (Lozupone \& Knight 2005) to calculate a distance matrix between all samples, which was then reduced in complexity through principal coordinate analysis (PCoA). 


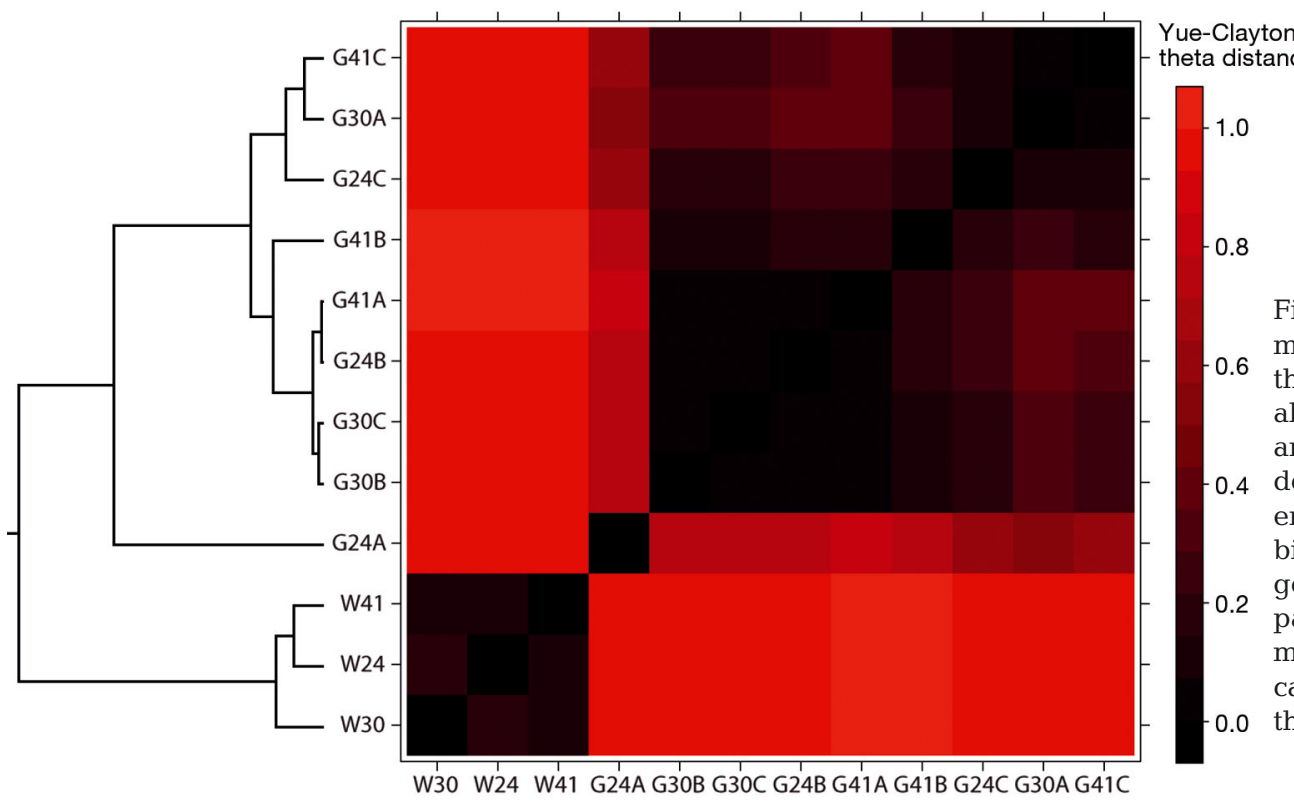

Fig. 1. Eunicella cavolini. Heatmap and tree of the Yue-Clayton theta distance measure between all samples. The intensity of black and red shading indicates the degree of similarity and difference, respectively, in the microbial communities. The tree was generated using the unweighted pair group method with arithmetic mean (UPGMA) hierarchical clustering of the Yue-Clayton theta values based on subsampled OTU counts

The result confirmed that although the gorgonian samples were clearly distinct from the water samples, they did not cluster by water depth (Fig. S2 in the Supplement). Additionally, they did not form a tight group as the water samples did, suggesting that they contained more variable assemblages of bacteria.

To determine the identities of the bacteria present in the gorgonians, we classified all $16 \mathrm{~S}$ sequences against the SILVA database (release 108; Pruesse et al. 2007). On the level of phyla, Proteobacteria were the dominant group, accounting for 60 to $93 \%$ of all tags in the gorgonian samples (Fig. 2A). In the water samples, Proteobacteria accounted for about onethird of all sequences, with Cyanobacteria and Bacteroidetes being the other major groups. Within Proteobacteria, Gammaproteobacteria was the dominant group among the gorgonians, representing $76 \%$ of all Proteobacteria. When looking at the relative contributions on the genus level, it becomes apparent that one genus within the Gammaproteobacteria, Endozoicomonas, was the most dominant group in the gorgonian bacterial community (Fig. 2B). While mostly absent from the seawater, Endozoicomonas accounted for 10 to $60 \%$ of the sequence reads from the gorgonian samples, with an average of $42 \%$. The sample with the lowest abundance of Endozoicomonas was G24A, the 'outlier' in the set, which instead was comprised of a high concentration of sequences from the genus Ruegeria, which had low abundance in or was absent from all other samples.

We also deduced the dominance of Endozoicomonas from the OTU data. Only 7 OTUs at the 0.03 difference level were present in all of the Eunicella cavolini samples tested (Table 2). These 7 OTUs, however, accounted for $64 \%$ of all reads in the 9 gorgonian samples, with OTU3 accounting for $61 \%$ of these reads. We classified OTU3 as Endozoicomonas. We also assigned 13 other OTUs to this genus; however, they contained $<6$ reads.

To identify additional OTUs that were significantly associated with the gorgonians, we used the statistical package indicspecies (De Cáceres \& Legendre 2009). Indicspecies tests the associations of species patterns with sample groups. Testing all gorgonian samples as one group against all water samples, we found that 786 OTUs were significantly associated $(p<0.05)$ with the water samples (data not shown), while 8 OTUs were significantly associated with the gorgonian group (Table S1 in the Supplement). Of these 8 , the OTU with the highest number of reads was again OTU3. The second highest was OTU41, part of the genus Halieda and also in the Gammaproteobacteria group. All other OTUs had total read numbers of $<130$ and were assigned to the genera Elizabethkingia, Arthrobacter, Stenotrophomonas, Acidovorax, an unclassified deltaproteobacterium, as well as one unclassified OTU. Four OTUs that were present in all gorgonian samples (Table 2) were not significantly associated with the gorgonians as compared to water (OTUs 1, 2, 41 and 111).

Grouping the gorgonians by the different depths, we found only a few OTUs that were significantly associated with a particular depth. Two OTUs, one classified as Aquimarina and the other unclassified but a member of Myxococcales, were found only 
A

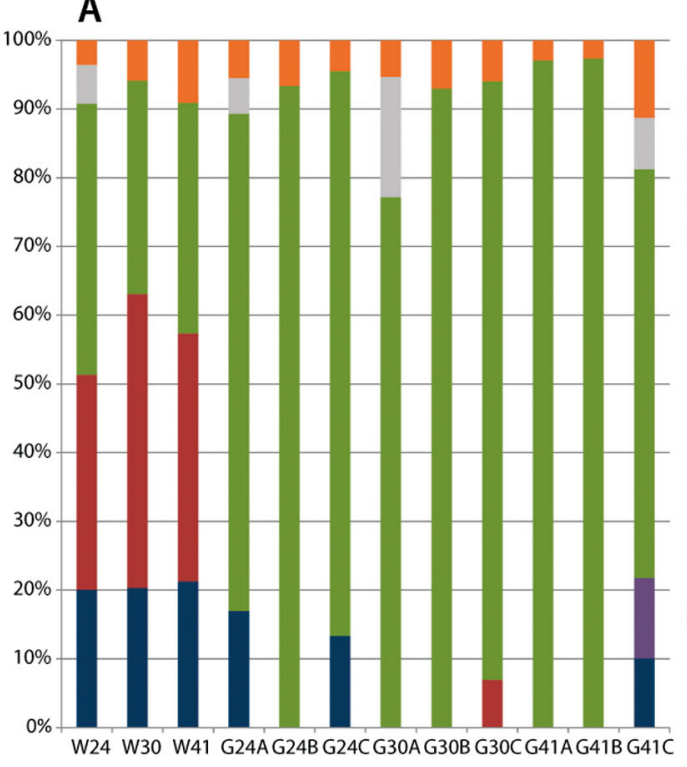

C

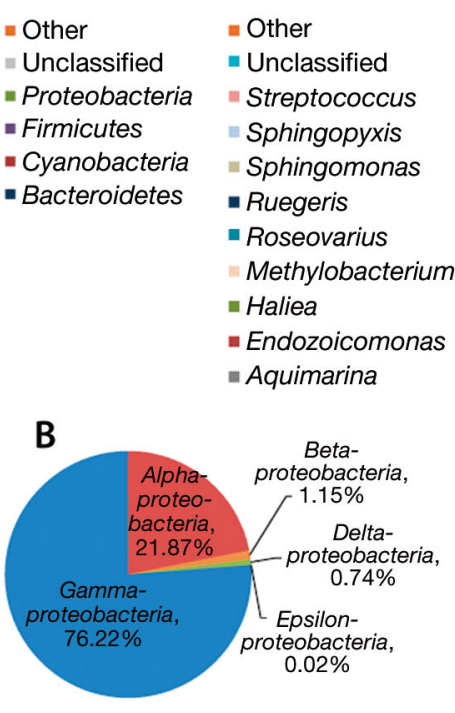

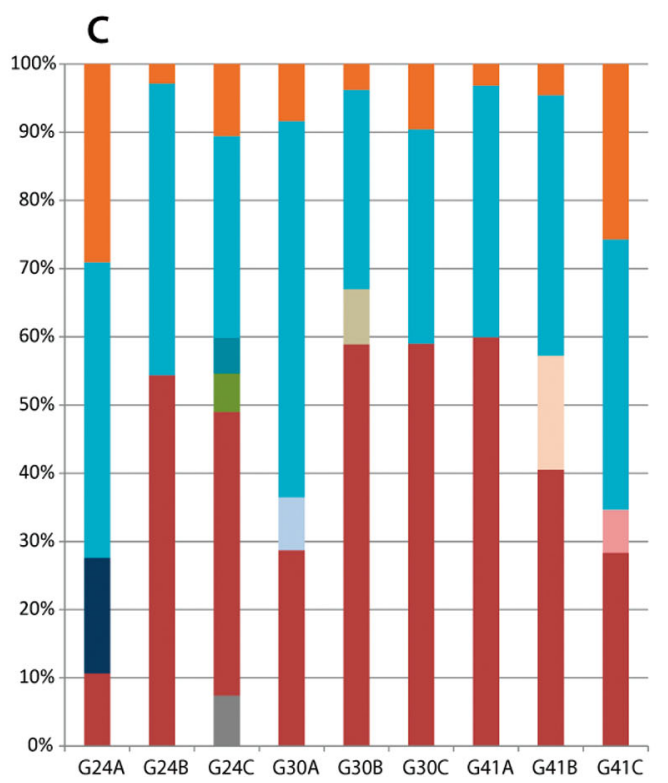

Fig. 2. Eunicella cavolini. Bacterial community compositions of water and gorgonian samples (indicated by the letters W and G, respectively, in the sample codes). (A) Relative contributions to samples on the phylum level. (B) Average composition of the Proteobacteria phylum in the gorgonian samples. (C) Relative contributions on the genus level in the gorgonian samples.

Phyla in (A) and genera in (B) contributing less than $5 \%$ of the reads have been grouped together in the 'other' category

Table 2. Eunicella cavolini. Summary of operational taxonomic units (OTUs) that were present in all samples of the gorgonian tested. For each OTU, the number of reads in each sample, the sum of reads for all samples and the percentage of all reads are shown. The lower panel shows the taxonomic assignment of the OTUs. Bootstrap values of less than 100 are shown in parentheses

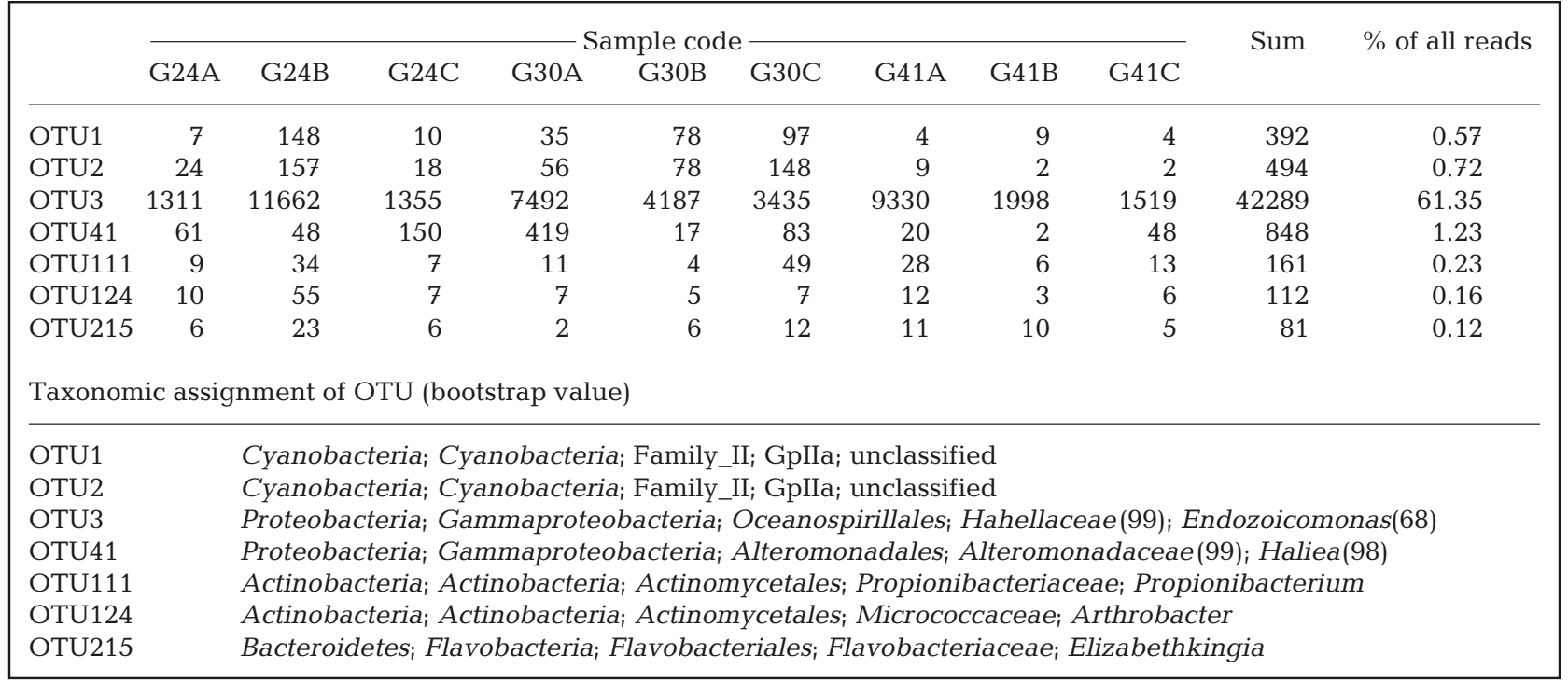

among the gorgonians at the $24 \mathrm{~m}$ depth (Table S1). The group of samples from $30 \mathrm{~m}$ contained an Endozoicomonas OTU that was not found among the other gorgonians, and the samples from $41 \mathrm{~m}$ were associated with one OTU that could not be assigned in the SILVA taxonomy database. However, none of these
OTUs was very abundant, with $<200$ reads per sample for Aquimarina and $<20$ for the other groups.

We sequenced the full-length 16S rRNA gene of the Endozoicomonas bacteria from Eunicella cavolini to analyze their phylogenetic position. Phylogenetic analysis revealed that they belong to the order 
Oceanospirillales and the family Hahellaceae, and most bacteria closely related to them are associated with marine invertebrates (Zielinski et al. 2009, Jensen et al. 2010). The closest relatives in the database were isolated from a Caribbean gorgonian, Gorgonia ventalina (98.3\% identity) (Sunagawa et al. 2010) and the arctic gorgonian Alcyonium antarcticum (93.3\% identity) (Webster \& Bourne 2007). Most other closely related bacteria were associated with either soft corals of the order Alcyonacea, such as the gorgonians, or scleractinian corals (Fig. S3 in the Supplement).

\section{DISCUSSION}

Although the sample set for this study was rather small, we produced, for the first time, a large dataset of $16 \mathrm{~S}$ reads from the bacterial community of Eunicella cavolini to understand the microbiology of a gorgonian from the Mediterranean Sea. We found that its bacterial community differs from that of the surrounding water and is less diverse. We therefore suggest that temperate octocorals exhibit a specific microbiome that is distinct from that of the surrounding water, as do tropical scleractinian corals (Rohwer et al. 2002).

We found between 100 and 785 OTUs at the 0.03 difference level in the gorgonians. The differences in OTUs between the individual samples were not dependent on the number of reads analyzed. For example, while we analyzed 7900 reads from sample G24A, which clustered into 785 OTUs, sample G24B had 13427 reads, but contained only 119 OTUs. To compare the diversity in Eunicella cavolini to other gorgonians, we reanalyzed sequences produced by Sunagawa et al. (2010) from the Caribbean coral Gorgonia ventalina using the same methods described above. The value for the Shannon diversity for this tropical gorgonian, 3.09, was in the same range as the values for E. cavolini (Table 1), with the caveat that the studies used different regions of the $16 \mathrm{~S}$ gene. For the bacterial community of scleractinian corals similar values from about 3 to 6 for the Shannon diversity index are reported (Bourne \& Munn 2005, Chen et al. 2011).

We sampled gorgonians from 3 different depths to determine whether their associated bacteria also differed, which might suggest that the bacteria were influenced by abiotic factors in the host's habitat. Alternatively, if the gorgonian host provided a stable environment to the bacteria that did not change with water depth, we would expect similar bacterial spe- cies to colonize host individuals. We found that while the bacterial community composition was more varied than that of the water, it did not vary according to depth. This pattern was independent of whether our comparisons took into account presence and/or abundance of OTUs. Eunicella cavolini is normally found from 20 to $100 \mathrm{~m}$, and there may be greater changes in bacterial assemblages as the depth increases beyond $41 \mathrm{~m}$; however, based on our results, we conclude that water depth is not a major factor in driving and structuring bacterial community composition in gorgonian corals.

The large variability between the samples was also reflected in the bacterial taxa shared among all individual Eunicella cavolini, with only 7 of 2067 OTUs found in all gorgonian samples. Although this overlap was quite small, one OTU was not only present in all samples, but made up a very large percentage of all sequences analyzed. The dominance of this OTU, classified as the genus Endozoicomonas, is the main feature that is common between all gorgonian samples we analyzed. The 6 other shared OTUs accounted for $<2 \%$ of all reads. These bacteria may play specific roles but are unlikely to provide basic functions that would require the symbiont to be present in large numbers. Furthermore, as we sampled in only one location, we cannot say whether these OTUs were present in samples taken from other parts of the Mediterranean.

One aim was to determine whether a core microbiome for a habitat or host existed. The core bacterial taxa contained in such a microbiome could be assumed to carry out vital functions for the host. Here, we defined the core microbiome by shared membership between samples.

We found that 7 OTUs were shared among all host individuals, with 6 of low abundance. The core microbiome of Eunicella cavolini may thus be restricted to the genus Endozoicomonas. Additional sampling that covers a larger geographical and temporal range would be required to determine whether a core microbiome truly exists. However, it is likely that the most abundant taxa are also the most persistent, as was found in a time series study in the North Sea (Gilbert et al. 2009).

The genus Endozoicomonas belongs to the family Hahellaceae and to the order Oceanospirillales, a group of heterotrophic, aerobic marine bacteria that are able to break down a wide range of organic compounds (Brenner et al. 2005). The Endozoicomonas species investigated here are part of a branch of the bacterial phylogenetic tree whose other members are also associated with marine invertebrates (Fig. S3 in 
the Supplement). Endozoicomonas have been found in sponges (some under the name Spongiobacter) (Thiel et al. 2007, Mohamed et al. 2008, Nishijima et al. 2013), bivalves (Zielinski et al. 2009, Jensen et al. 2010), ascidians (Martínez-García et al. 2007), a nudibranch (Kurahashi \& Yokota 2007), polychaetes (Goffredi et al. 2007), sea anemones (Schuett et al. 2007, Du et al. 2010), starfish (Choi et al. 2010), scleractinian corals (Bourne \& Munn 2005, Bourne et al. 2008, Hansson et al. 2009, Littman et al. 2009, Raina et al. 2009, Sunagawa et al. 2010, Yang et al. 2010, Speck \& Donachie 2012), and different tropical gorgonians and other soft corals (Webster \& Bourne 2007, Sunagawa et al. 2010). In the Caribbean gorgonian Gorgonia ventalina, the most common bacteria are Endozoicomonas. These bacteria were the most closely related to the bacteria from Eunicella cavolini in our phylogenetic tree of the Encozoicomonas (Fig. S3 in the Supplement; see also Sunagawa et al. 2010). The fact that the 2 closest bacterial relatives in Fig. S3 originate from gorgonians, but from very different habitats and geographic ranges, suggests an evolutionarily old association between the gorgonian hosts and the Endozoicomonas. If the association were of more recent origin, it would be expected that the Endozoicomonas in G. ventalina would be more closely related to those of other Caribbean species, such as the scleractinian corals found there. While we report on a sample of limited geographic range, we expect the dominance of the Endozoicomonas in the microbiology of E. Cavolini to be present across the range of the species, given that it seems to be a feature even in related and geographically distant gorgonian species.

While Endozoicomonas bacteria have been shown to be intranuclear parasites in Bathymodiolus mussels (Zielinski et al. 2009), they seem to form symbiotic associations in all other documented cases, although the basis of the symbiosis is not known for most examples. One exception is the polychaete Osedax, which lives on bones at whale fall sites. Symbiotic Endozoicomonas in Osedax appear to break down compounds in the bones and provide nutrition to their host (Goffredi et al. 2005). Endozoicomonas have also been implicated in sulfur cycling in corals, as they are able to metabolize dimethylsulfoniopropionate (DMSP; Raina et al. 2009, 2010). DMSP is produced by photosynthetic algae, which provide food for the filterfeeding Eunicella cavolini. It is thus probable that Endozoicomonas also provide DMSP degradation to temperate gorgonians.

Measured by their widespread abundance in marine invertebrates and their dominance in the struc- ture of the microbiomes of species such as Eunicella cavolini, bacteria of the Endozoicomonas group likely have an important ecological function. As this association is so widespread among hosts of different phyla, it either arose multiple times throughout evolutionary history or, more likely, is very old.

In summary, we examined associations between temperate anthozoans and bacteria in this study. Our data can provide a baseline for further investigations of changes in the composition and functions of microbiota.

Acknowledgements. We thank David Ngugi for valuable discussions and critical reading of the manuscript, Fabian Staubach for helpful advice, the diver team of the CSM and David Luquet from the Observatoire Océanologique de Villefranche-sur-Mer for sampling and Cécile Rottier for technical help. This work was supported by an External Laboratory Access grant by King Abdullah University of Science and Technology to T.B.

\section{LITERATURE CITED}

Ballesteros E (2006) Mediterranean coralligenous assemblages: A synthesis of present knowledge. In: Gibson RN, Atkinson RJA, Gordon JDM (eds) Oceanography and marine biology: an annual review, Vol 44. CRC Press, Boca Raton, FL, p 123-195

> Bally M, Garrabou J (2007) Thermodependent bacterial pathogens and mass mortalities in temperate benthic communities: a new case of emerging disease linked to climate change. Glob Change Biol 13:2078-2088

Berry D, Mahfoudh KB, Wagner M, Loy A (2011) Barcoded primers used in multiplex amplicon pyrosequencing bias amplification. Appl Environ Microbiol 77:7846-7849

$>$ Bourne DG, Munn CB (2005) Diversity of bacteria associated with the coral Pocillopora damicornis from the Great Barrier Reef. Environ Microbiol 7:1162-1174

> Bourne DG, Iida Y, Uthicke S, Smith-Keune C (2008) Changes in coral-associated microbial communities during a bleaching event. ISME J 2:350-363

- Bramanti L, Iannelli M, Santangelo G (2009) Mathematical modelling for conservation and management of gorgonians corals: youngs and olds, could they coexist? Ecol Modell 220:2851-2856

Brenner DJ, Krieg NR, Garrity GM, Staley JT (2005) Bergey's manual of systematic bacteriology: the proteobacteria, 2nd edn. Springer, New York, NY

$>$ Bruno JF, Selig ER, Casey KS, Page CA and others (2007) Thermal stress and coral cover as drivers of coral disease outbreaks. PLoS Biol 5:e124

> Bustillos-Guzmán J, Claustre H, Marty JC (1995) Specific phytoplankton signatures and their relationship to hydrographic conditions in the coastal northwestern Mediterranean Sea. Mar Ecol Prog Ser 124:247-258

Carpine C, Grasshoff M (1975) Les gorgonaires de la Méditerranée. Bull Inst Oceanogr 71:1-140

Cerrano C, Bavestrello G, Bianchi CN, Cattaneo-vietti R and others (2000) A catastrophic mass-mortality episode of gorgonians and other organisms in the Ligurian Sea (Northwestern Mediterranean), summer 1999. Ecol Lett 3:284-293 
Chao A (1984) Nonparametric estimation of the number of classes in a population. Scand J Stat 11:265-270

$>$ Chen CP, Tseng CH, Chen CA, Tang SL (2011) The dynamics of microbial partnerships in the coral Isopora palifera. ISME J 5:728-740

Choi EJ, Kwon HC, Sohn YC, Yang HO (2010) Kistimonas asteriae gen. nov., sp. nov., a gammaproteobacterium isolated from Asterias amurensis. Int J Syst Evol Microbiol 60:938-943

Cimino G, De Rosa S, De Stefano S (1984) Antiviral agents from a gorgonian, Eunicella cavolini. Cell Mol Life Sci 40:339-340

> Coma R, Linares C, Ribes M, Diaz D, Garrabou J, Ballesteros E (2006) Consequences of a mass mortality in populations of Eunicella singularis (Cnidaria: Octocorallia) in Menorca (NW Mediterranean). Mar Ecol Prog Ser 327: $51-60$

> Couch CS, Mydlarz LD, Harvell CD, Douglas NL (2008) Variation in measures of immunocompetence of sea fan coral, Gorgonia ventalina, in the Florida Keys. Mar Biol 155:281-292

> De Cáceres M, Legendre P (2009) Associations between species and groups of sites: indices and statistical inference. Ecology 90:3566-3574

> Du Z, Zhang W, Xia H, Lü G, Chen G (2010) Isolation and diversity analysis of heterotrophic bacteria associated with sea anemones. Acta Oceanol Sin 29:62-69

$>$ Dubilier N, Bergin C, Lott C (2008) Symbiotic diversity in marine animals: the art of harnessing chemosynthesis. Nat Rev Microbiol 6:725-740

- Edgar RC, Haas BJ, Clemente JC, Quince C, Knight R (2011) UCHIME improves sensitivity and speed of chimera detection. Bioinformatics 27:2194-2200

Ferrier-Pagès C, Leclercq N, Jaubert J, Pelegrí SP (2000) Enhancement of pico- and nanoplankton growth by coral exudates. Aquat Microb Ecol 21:203-209

Frias-Lopez J, Zerkle AL, Bonheyo GT, Fouke BW (2002) Partitioning of bacterial communities between seawater and healthy, black band diseased, and dead coral surfaces. Appl Environ Microbiol 68:2214-2228

> Garrabou J, Harmelin JG (2002) A 20-year study on lifehistory traits of a harvested long-lived temperate coral in the NW Mediterranean: insights into conservation and management needs. J Anim Ecol 71:966-978

- Garrabou J, Coma R, Bensoussan N, Bally M and others (2009) Mass mortality in Northwestern Mediterranean rocky benthic communities: effects of the 2003 heat wave. Glob Change Biol 15:1090-1103

Gilbert JA, Field D, Swift P, Newbold L and others (2009) The seasonal structure of microbial communities in the Western English Channel. Environ Microbiol 11: 3132-3139

> Gili JM, Coma R (1998) Benthic suspension feeders: their paramount role in littoral marine food webs. Trends Ecol Evol 13:316-321

> Gili JM, Ros J (1985) Study and cartography of the benthic communities of Medes Islands (NE Spain). PSZN I: Mar Ecol 6:219-238

Gili JM, Murillo J, Ros J (1989) The distribution pattern of benthic Cnidarians in the Western Mediterranean. Sci Mar 53:19-35

Goffredi SK, Orphan VJ, Rouse GW, Jahnke L and others (2005) Evolutionary innovation: a bone-eating marine symbiosis. Environ Microbiol 7:1369-1378

Goffredi SK, Johnson SB, Vrijenhoek RC (2007) Genetic diversity and potential function of microbial symbionts associated with newly discovered species of Osedax polychaete worms. Appl Environ Microbiol 73:2314-2323

Guindon S, Gascuel O (2003) A simple, fast, and accurate algorithm to estimate large phylogenies by maximum likelihood. Syst Biol 52:696-704

> Hansson L, Agis M, Maier C, Weinbauer MG (2009) Community composition of bacteria associated with coldwater coral Madrepora oculata: within and between colony variability. Mar Ecol Prog Ser 397:89-102

Harmelin JG (1995) Gorgones: les plus beaux ornements de la Méditerranée sont-ils menacés ? Océanorama 24:3-9

Huse SM, Welch DM, Morrison HG, Sogin ML (2010) Ironing out the wrinkles in the rare biosphere through improved OTU clustering. Environ Microbiol 12:1889-1898

- Jensen S, Duperron S, Birkeland NK, Hovland M (2010) Intracellular Oceanospirillales bacteria inhabit gills of Acesta bivalves. FEMS Microbiol Ecol 74:523-533

Jones CG, Lawton JH, Shachak M (1994) Organisms as ecosystem engineers. Oikos 69:373-386

Kurahashi M, Yokota A (2007) Endozoicomonas elysicola gen. nov., sp. nov., a gammaproteobacterium isolated from the sea slug Elysia ornata. Syst Appl Microbiol 30: 202-206

Lacroix G, Nival P (1998) Influence of meteorological variability on primary production dynamics in the Ligurian Sea (NW Mediterranean Sea) with a 1D hydrodynamic/ biological model. J Mar Syst 16:23-50

La Rivière M, Garrabou J, Bally M (2010) Spatial and temporal analysis of bacterial diversity associated with the mediterranean gorgonian Paramuricea clavata. Rapp Comm Int Mer Médit 39:769

> Lesser MP, Mazel CH, Gorbunov MY, Falkowski PG (2004) Discovery of symbiotic nitrogen-fixing cyanobacteria in corals. Science 305:997-1000

- Linares C, Doak DF (2010) Forecasting the combined effects of disparate disturbances on the persistence of long-lived gorgonians: a case study of Paramuricea clavata. Mar Ecol Prog Ser 402:59-68

> Linares C, Coma R, Diaz D, Zabala M, Hereu B, Dantart L (2005) Immediate and delayed effects of a mass mortality event on gorgonian population dynamics and benthic community structure in the NW Mediterranean Sea. Mar Ecol Prog Ser 305:127-137

> Linares C, Doak DF, Coma R, Díaz D, Zabala M (2007) Life history and viability of a long-lived marine invertebrate: the octocoral Paramuricea clavata. Ecology 88:918-928

> Littman RA, Willis BL, Bourne DG (2009) Bacterial communities of juvenile corals infected with different Symbiodinium (dinoflagellate) clades. Mar Ecol Prog Ser 389:45-59

> Lozupone C, Knight R (2005) UniFrac: a new phylogenetic method for comparing microbial communities. Appl Environ Microbiol 71:8228-8235

Ludwig W, Strunk O, Westram R, Richter L, and others (2004) ARB: a software environment for sequence data. Nucleic Acids Res 32:1363-1371

Martínez-García M, Díaz-Valdés M, Wanner G, RamosEsplá A, Antón J (2007) Microbial community associated with the colonial ascidian Cystodytes dellechiajei. Environ Microbiol 9:521-534

> McFall-Ngai M (2008) Host-microbe symbiosis: the squidVibrio association - a naturally occurring, experimental model of animal/bacterial partnerships. Adv Exp Med Biol 635:102-112

Mohamed NM, Cicirelli EM, Kan J, Chen F, Fuqua C, Hill 
RT (2008) Diversity and quorum-sensing signal production of Proteobacteria associated with marine sponges. Environ Microbiol 10:75-86

Morrow KM, Moss AG, Chadwick NE, Liles MR (2012) Bacterial associates of two Caribbean coral species reveal species-specific distribution and geographic variability. Appl Environ Microbiol 78:6438-6449

Mydlarz LD, Holthouse SF, Peters EC, Harvell CD (2008) Cellular responses in sea fan corals: granular amoebocytes react to pathogen and climate stressors. PLoS ONE 3:e1811

Nishijima M, Adachi K, Katsuta A, Shizuri Y, Yamasato K (2013) Endozoicomonas numazuensis sp. nov., a gammaproteobacterium isolated from marine sponges, and emended description of the genus Endozoicomonas Kurahashi and Yokota 2007. Int J Syst Evol Microbiol 63: 709-714

Oksanen J, Blanchet FG, Kindt R, Legendre P and others (2012) vegan: Community Ecology Package, http:// vegan.r-forge.r-project.org/

Pantos O, Cooney RP, Le Tissier MDA, Barer MR, O'Donnell AG, Bythell JC (2003) The bacterial ecology of a plaguelike disease affecting the Caribbean coral Montastrea annularis. Environ Microbiol 5:370-382

Pruesse E, Quast C, Knittel K, Fuchs BM, Ludwig W, Peplies J, Glöckner FO (2007) SILVA: a comprehensive online resource for quality checked and aligned ribosomal RNA sequence data compatible with ARB. Nucleic Acids Res 35:7188-7196

Raina JB, Tapiolas D, Willis BL, Bourne DG (2009) Coralassociated bacteria and their role in the biogeochemical cycling of sulfur. Appl Environ Microbiol 75:3492-3501

Raina JB, Dinsdale EA, Willis BL, Bourne DG (2010) Do the organic sulfur compounds DMSP and DMS drive coral microbial associations? Trends Microbiol 18:101-108

R Core Team (2012) R: a language and environment for statistical computing. R Foundation for Statistical Computing, Vienna

Ritchie KB (2006) Regulation of microbial populations by coral surface mucus and mucus-associated bacteria. Mar Ecol Prog Ser 322:1-14

Rivest EB, Baker DM, Rypien KL, Harvell CD (2010) Nitrogen source preference of Aspergillus sydowii, an infective agent associated with aspergillosis of sea fan corals. Limnol Oceanogr 55:386-392

> Rohwer F, Seguritan V, Azam F, Knowlton N (2002) Diversity and distribution of coral-associated bacteria. Mar Ecol Prog Ser 243:1-10

Rouse GW, Goffredi SK, Vrijenhoek RC (2004) Osedax: bone-eating marine worms with dwarf males. Science 305:668-671

Roussis V, Chinou IB, Tsitsimpikou C, Vagias C, Petrakis PV (2001) Antibacterial activity of volatile secondary metabolites from Caribbean soft corals of the genus Gorgonia. Flavour Fragrance J 16:364-366

Editorial responsibility: Karen Miller, Hobart, Tasmania, Australia
Santangelo G, Bramanti L, Iannelli M (2007) Population dynamics and conservation biology of the over-exploited Mediterranean red coral. J Theor Biol 244:416-423

Schloss PD, Westcott SL, Ryabin T, Hall JR and others (2009) Introducing mothur: open-source, platformindependent, community-supported software for describing and comparing microbial communities. Appl Environ Microbiol 75:7537-7541

> Schuett C, Doepke H, Grathoff A, Gedde M (2007) Bacterial aggregates in the tentacles of the sea anemone Metridium senile. Helgol Mar Res 61:211-216

Sharp KH, Distel D, Paul VJ (2012) Diversity and dynamics of bacterial communities in early life stages of the Caribbean coral Porites astreoides. ISME J 6:790-801

Shashar N, Cohen Y, Loya Y, Sar N (1994) Nitrogen fixation (acetylene reduction) in stony corals: evidence for coralbacteria interactions. Mar Ecol Prog Ser 111:259-264

Speck MD, Donachie SP (2012) Widespread Oceanospirillaceae bacteria in Porites spp. J Mar Biol 2012,746720

> Sunagawa S, Woodley CM, Medina M (2010) Threatened corals provide underexplored microbial habitats. PLoS ONE 5:e9554

- Tamura K, Peterson D, Peterson N, Stecher G, Nei M, Kumar S (2011) MEGA5: molecular evolutionary genetics analysis using maximum likelihood, evolutionary distance, and maximum parsimony methods. Mol Biol Evol 28: 2731-2739

> Thiel V, Leininger S, Schmaljohann R, Brümmer F, Imhoff JF (2007) Sponge-specific bacterial associations of the Mediterranean sponge Chondrilla nucula (Demospongiae, Tetractinomorpha). Microb Ecol 54:101-111

- Webster NS, Bourne DG (2007) Bacterial community structure associated with the Antarctic soft coral, Alcyonium antarcticum. FEMS Microbiol Ecol 59:81-94

> Weinbauer MG, Velimirov B (1995) Biomass and secondary production of the temperate gorgonian coral Eunicella cavolini (Coelenterata: Octocorallia). Mar Ecol Prog Ser 121:211-216

Wild C, Huettel M, Klueter A, Kremb SG, Rasheed MYM, Jorgensen BB (2004) Coral mucus functions as an energy carrier and particle trap in the reef ecosystem. Nature 428:66-70

- Williams WM, Viner AB, Broughton WJ (1987) Nitrogen fixation (acetylene reduction) associated with the living coral Acropora variabilis. Mar Biol 94:531-535

> Yang CS, Chen MH, Arun AB, Chen CA, Wang JT, Chen WM (2010) Endozoicomonas montiporae sp. nov., isolated from the encrusting pore coral Montipora aequituberculata. Int J Syst Evol Microbiol 60:1158-1162

> Yue J, Clayton M (2005) A similarity measure based on species proportions. Commun Stat-Theory M 34:2123-2131

Zielinski FU, Pernthaler A, Duperron S, Raggi L, Giere O, Borowski C, Dubilier N (2009) Widespread occurrence of an intranuclear bacterial parasite in vent and seep bathymodiolin mussels. Environ Microbiol 11:1150-1167

Submitted: August 6, 2012; Accepted: November 27, 2012 Proofs received from author(s): March 10, 2013 